\title{
Research on the Effectiveness of the Actuating Element of the Electro Control System for the Powered Roof Support
}

\author{
Dawid Szurgacz ${ }^{1 *}$, Jarosław Brodny ${ }^{2}$ \\ ${ }^{1}$ Center of Hydraulics DOH Ltd, ul. Konstytucji 147, 41-906 Bytom, Poland \\ ${ }^{2}$ Silesian University of Technology, Faculty of Organization and Management, Roosevelta 26, 41-800 \\ Zabrze, Poland
}

\begin{abstract}
The development of high-efficiency longwall complexes in underground mining enforces the introduction of new control systems for the operation of a powered roof support. The most important stage when creating a new control system for a powered longwall system is to determine the time dependencies between the setting off of the function and its actual implementation by the control elements of the control system. Electro hydraulic control of the powered roof support has a number of advantages as compared to the manually operated distributor blocks. The most important are: higher supply pressure, reduction of the amount of force needed to override the support, the ability to adjust the power parameters to absorbency of the support's actuators and their number, modular construction of control and executive dividers allowing customization construction of electro hydraulic control units and requirements resulting from the construction of the section. The presented research is focused on the analysis of time relations between the setting off of the control function and its actual implementation. This is the time from the moment of supplying power to the solenoid valve until the solenoid valve is opened. This dependence is of extremely significant as it determines the effectiveness of the entire control system.
\end{abstract}

Keywords: solenoid valve, powered roof support, mining operation, electrohydraulic control.

\section{Introduction}

A number of requirements must be met in order to introduce a new control system of a powered roof support. These requirements result from standards related to the design of machine safe control systems. Standards technically harmonized with the Machinery Directive (2006/42/EC) constitute a technical interpretation of the fulfilment of safety requirements.

The extraction of hard coal in Poland is carried out by 8 entities: Polska Grupa Górnicza, Jastrzębska Spółka Węglowa, Lubelski Węgiel Bogdanka, Tauron Wydobycie, Węglokoks Kraj and private factories - PG Silesia, Siltech and Eko-Plus. These companies face challenges such as minimizing costs, increasing the quality of the final product, increasing the company's income, maintaining jobs and creating new ones as the market develops. It is possible to achieve by introducing innovative solutions. In order for such solutions to be introduced, these enterprises must conduct advanced research work, have

*Corresponding author: dawidszurgacz@doh.com.pl 
appropriate technical equipment as well as financial and organizational capabilities. Only then is it possible to develop and implement solutions that can bring satisfactory results. This can improve the work safety of the company, increase its efficiency and generally improve the efficiency of the entire production process. The introduction of innovative methods affects the development of competitive solutions in the industry and the entire global economy.

The development of intelligent control systems for powered roof support is part of these trends. The development and application of such a control will allow optimization of the work of the roof support section, increase safety and improve the efficiency of the mining process. In particular, it concerns the efficiency of mining machines $[3,6]$ and ensuring process safety in an environment exposed to a range of natural hazards [1, 2, 4]. Optimizing this process also requires an appropriate philosophical approach to this problem [5]. The necessity to develop such a system results therefore from real technical needs related to the development of mining operations and work safety. At the same time, high competition on the market, concentration of mining, deterioration of mining and geological conditions due to deeper exploitation, cause that the solution must be put into practice as soon as possible. For this reason, the Authors decided to develop a new control system for the powered roof support. One of the stages of the implementation of this project is the study of individual elements of the system. This is to control their capabilities and to identify possible actions to be taken to improve the performance of the tested components. The article presents the results of tests on one of the main elements of the solenoid valve, which is to form the basis of the entire control system responsible for execution of tasks. The effectiveness of this element is crucial. It decides about the efficiency and effectiveness of the entire electrohydraulic valve. The research covered the determination of the time dependence between the setting off of a specific function controlling the powered roof support and its actual implementation by the system's executive elements. A specialist measuring system and test stand were developed and constructed for the research. The work discusses these systems and presents the results of the research.

\section{Methodology and scope of research}

In order to check the effectiveness of the work and develop the electro hydraulic valve, it is necessary to carry out its tests during the operation of the section. For this purpose, the valve was mounted in the powered roof support section and subjected to tests in a testing station. The powered roof support with marked hydraulic elements included in the tests is presented in Figure 1.

The test method consists in the analysis of time dependencies between the setting off of a specific control function and its actual implementation by control elements of the control system. In practice, this means the need to determine the actual time of executing a specific control function. Setting such a function is not easy. Until now, despite many works in this area, it has not been clearly defined.

In the presented example, the research was carried out on the basis of an innovative recording and measuring system, which is designed to determine, among others, the static and dynamic characteristics of the control functions of the powered roof support. It also allows testing control elements and visualization of their work parameters. The developed application enables work in the slave mode performing certain functions of the support section and in the master mode enabling the setting off of specific functions controlling the roof support by means of a virtual keyboard [7]. 


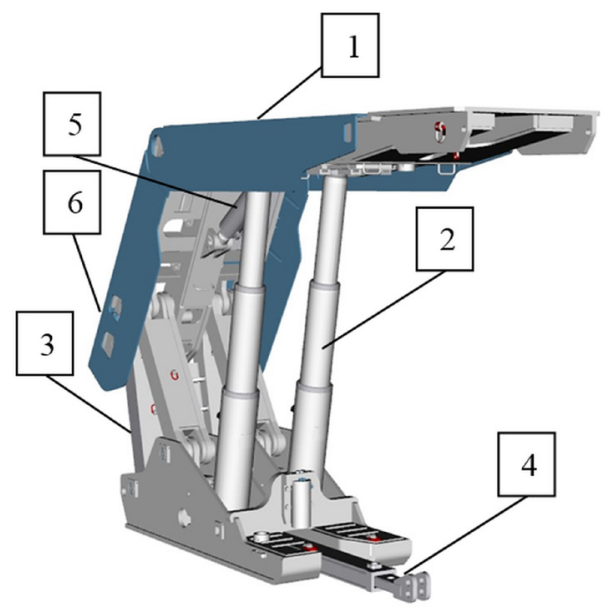

Fig. 1. The powered roof support with marked hydraulic elements included in the tests: 1 - canopy, 2 - legs, 3 - lemniscate mechanism, 4 - shifter with a beam connected to the floor bases 5 - canopy's support cylinder, 6 - caving shield .

Research on the determination of time dependencies between the setting off of a specific control function and its actual implementation by the control elements of the control system was carried out successively for various types of solenoid valve control:

- standard power supply,

- FC Controller,

- cRIO Controller.

The tests were carried out for various values of supply voltage $(12 \mathrm{~V}, 11 \mathrm{~V}, 10 \mathrm{~V}, 9 \mathrm{~V}$ and $8 \mathrm{~V})$. A few basic operating states of the roof support were also included. For these states, the operating times of the control system were determined. The tested functions included:

- sliding down the legs,

- sliding out the legs,

- sliding out the canopy support's actuator,

- sliding down the canopy support's actuator, sliding down the shifter,

- sliding out the shifter.

Flow chart of the metering unit included in the tests is presented in Figure 2.

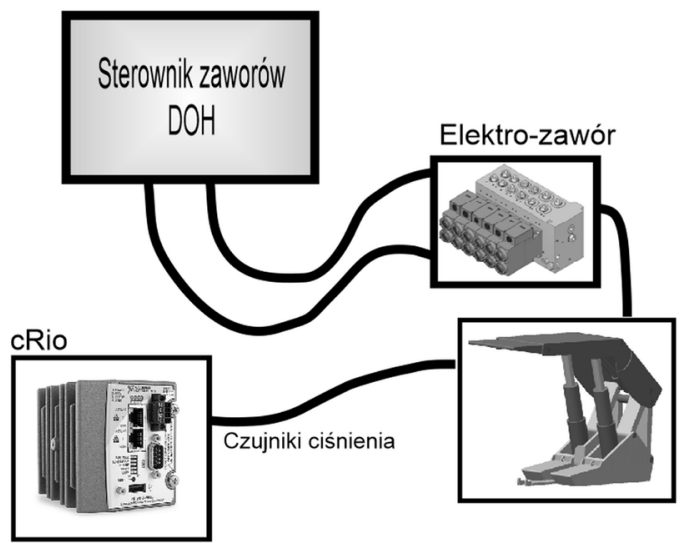

Fig. 2. Flow-chart of the metering system included in the tests. 


\section{Results and discussions}

The determination of the expected dependencies and their reliability depend on the correctness of the measurements carried out. For this reason, particular attention was paid during the research to the diligence of their implementation.

The obtained test results are listed in Tables 1,2 and 3 The tests included determining the values of $T_{1}$ and $T_{z}$ times.

The results obtained were compiled depending on various voltage values given on the valve, various types of power supply (full and PWM supply) and the type of valve controller (laboratory power supply, FC controller, cRIO controller).

Figure 3 presents an example view of the registered course of the examined quantities. Symbols:

- Plot 0 and plot 1 , the pressure coming from the valve piston above the piston and under the piston,

- Plot 3 and plot 4, coil voltage of solenoid valves,

- T1, the time from the moment of supplying power to the solenoid valve until the solenoid valve is opened,

- Tz delay time (response of the hydraulic system to power off).

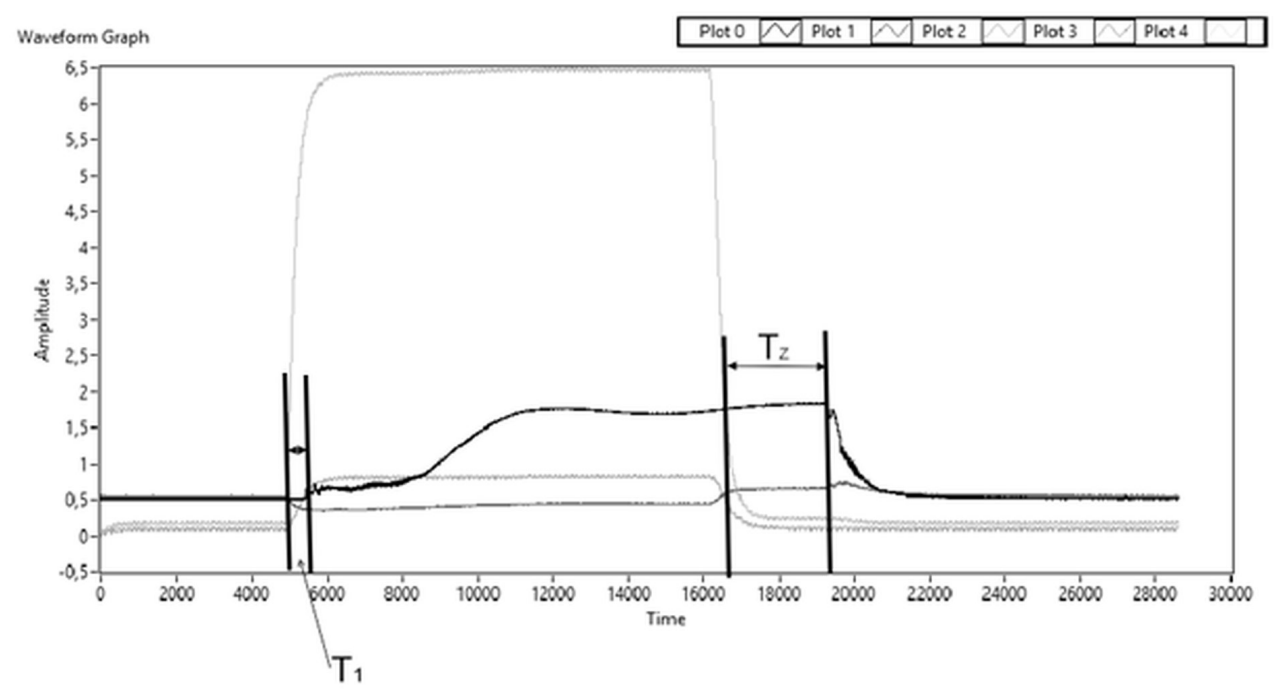

Fig. 3. An exemplary view of the registered course of the tested parameters of the solenoid valve operation/

Obtained results from the conducted research on the determination of time dependencies between setting off of a specific control function and its actual implementation by the executive elements of the control system are presented in Tables 1, 2 and 3 . The first table summarizes the test results for a standard power supply used to power the solenoid valve. Table 2 presents the results for the FC type controller; and Table 3 for the cRIO driver. 
Table 1. Measurement results for solenoid valve's opening time and delay for different values of supply voltages and functions of the roof support section for a system with a standard power supply.

\begin{tabular}{|c|c|c|c|}
\hline T1 & $\mathbf{T z}$ & Voltage [V] & $\begin{array}{l}\text { Performed } \\
\text { Function }\end{array}$ \\
\hline 0.088708 & 0.267824 & 12 & \multirow{5}{*}{ Sliding down the legs } \\
\hline 0.145427 & 0.253879 & 11 & \\
\hline 0.15596 & 0.250364 & 10 & \\
\hline 0.171525 & 0.271143 & 9 & \\
\hline 0.19416 & 0.249086 & 8 & \\
\hline 0.110516 & 0.444736 & 12 & \multirow{5}{*}{ Sliding out the legs } \\
\hline 0.119756 & 0.462774 & 11 & \\
\hline 0.120445 & 0.429496 & 10 & \\
\hline 0.124931 & 0.43428 & 9 & \\
\hline 0.136299 & 0.426167 & 8 & \\
\hline 0.10645 & 0.345739 & 12 & \multirow{5}{*}{$\begin{array}{l}\text { Sliding down the canopy } \\
\text { support's actuator }\end{array}$} \\
\hline 0.088209 & 0.346074 & 11 & \\
\hline 0.084273 & 0.350644 & 10 & \\
\hline 0.058972 & 0.322173 & 9 & \\
\hline 0.050656 & 0.256144 & 8 & \\
\hline 0.083731 & 0.299999 & 12 & \multirow{5}{*}{$\begin{array}{l}\text { Sliding out the canopy } \\
\text { support's actuator, }\end{array}$} \\
\hline 0.090761 & 0.312507 & 11 & \\
\hline 0.094807 & 0.290171 & 10 & \\
\hline 0.109769 & 0.260566 & 9 & \\
\hline 0.119354 & 0.275604 & 8 & \\
\hline 0.128627 & 0.29553 & 12 & \multirow{5}{*}{ Shifter - sliding out } \\
\hline 0.081501 & 0.28151 & 11 & \\
\hline 0.079967 & 0.276887 & 10 & \\
\hline 0.103493 & 0.269911 & 9 & \\
\hline 0.138237 & 0.250953 & 8 & \\
\hline 0.084833 & 0.352149 & 12 & \multirow{5}{*}{ Shifter - sliding down } \\
\hline 0.092144 & 0.325861 & 11 & \\
\hline 0.091811 & 0.325877 & 10 & \\
\hline 0.128072 & 0.310549 & 9 & \\
\hline 0.129269 & 0.2726 & 8 & \\
\hline
\end{tabular}


Table 2. Measurement results for solenoid valve's opening time and delay for different values of supply voltages and functions of the roof support section for a system with an FC controller/

\begin{tabular}{|c|c|c|c|}
\hline T1 & $\mathbf{T z}$ & Voltage [V] & $\begin{array}{l}\text { Performed } \\
\text { Function }\end{array}$ \\
\hline 0.105031 & 0.295611 & 12 & \multirow{5}{*}{ Sliding down the legs } \\
\hline 0.123393 & 0.294231 & 11 & \\
\hline 0.139552 & 0.278103 & 10 & \\
\hline 0.158649 & 0.270531 & 9 & \\
\hline 0.179949 & 0.263096 & 8 & \\
\hline 0.124245 & 0.289384 & 12 & \multirow{5}{*}{$\begin{array}{l}\text { Sliding down the legs with } \\
\text { PWM signal }\end{array}$} \\
\hline 0.125321 & 0.280281 & 11 & \\
\hline 0.132207 & 0.263564 & 10 & \\
\hline 0.159236 & 0.2515 & 9 & \\
\hline 0.172186 & 0.239014 & 8 & \\
\hline 0.132207 & 0.396409 & 12 & \multirow{5}{*}{$\begin{array}{c}\text { Sliding out the legs with PWM } \\
\text { signal }\end{array}$} \\
\hline 0.140455 & 0.315023 & 11 & \\
\hline 0.140455 & 0.310134 & 10 & \\
\hline 0.17444 & 0.305877 & 9 & \\
\hline 0.181784 & 0.27426 & 8 & \\
\hline 0.087404 & 0.32254 & 12 & \multirow{5}{*}{ Sliding out the legs } \\
\hline 0.104664 & 0.370331 & 11 & \\
\hline 0.128535 & 0.327071 & 10 & \\
\hline 0.129453 & 0.307621 & 9 & \\
\hline 0.161954 & 0.29427 & 8 & \\
\hline 0.088689 & 0.409291 & 12 & \multirow{5}{*}{$\begin{array}{l}\text { Sliding down the canopy } \\
\text { support's actuator }\end{array}$} \\
\hline 0.092545 & 0.378858 & 11 & \\
\hline 0.124862 & 0.302309 & 10 & \\
\hline 0.118619 & 0.311947 & 9 & \\
\hline 0.161954 & 0.292141 & 8 & \\
\hline 0.092545 & 0.274066 & 12 & \multirow{5}{*}{$\begin{array}{l}\text { Sliding out the canopy } \\
\text { support's actuator, }\end{array}$} \\
\hline 0.102828 & 0.269387 & 11 & \\
\hline 0.122292 & 0.253141 & 10 & \\
\hline 0.142123 & 0.255114 & 9 & \\
\hline 0.184024 & 0.23987 & 8 & \\
\hline
\end{tabular}

Table 3. Measurement results for solenoid valve's opening time and delay for different values of supply voltages and functions of the roof support section for a system with a cRIO controller.

\begin{tabular}{|c|c|c|c|}
\hline T1 & Tz & Voltage [V] & \multirow{2}{*}{$\begin{array}{c}\text { Performed } \\
\text { Function }\end{array}$} \\
\hline 0.120126 & 0.247556 & 12 & \multirow{2}{*}{ Sliding down the legs } \\
\hline 0.136259 & 0.236491 & 11 & \\
\hline 0.152467 & 0.240037 & 10 & \\
\hline 0.141379 & 0.243583 & 9 & \\
\hline
\end{tabular}




\begin{tabular}{|c|c|c|c|}
\hline 0.175569 & 0.235847 & 8 & \\
\hline 0.092404 & 0.38193 & 12 & \multirow{5}{*}{$\begin{array}{l}\text { Sliding down the legs with } \\
\text { PWM signal }\end{array}$} \\
\hline 0.120126 & 0.361991 & 11 & \\
\hline 0.112364 & 0.375576 & 10 & \\
\hline 0.141379 & 0.34393 & 9 & \\
\hline 0.175569 & 0.329356 & 8 & \\
\hline 0.097579 & 0.251333 & 12 & \multirow{5}{*}{$\begin{array}{c}\text { Sliding out the legs with PWM } \\
\text { signal }\end{array}$} \\
\hline 0.106191 & 0.237299 & 11 & \\
\hline 0.110516 & 0.242414 & 10 & \\
\hline 0.162631 & 0.226083 & 9 & \\
\hline 0.170024 & 0.243211 & 8 & \\
\hline 0.081316 & 0.363696 & 12 & \multirow{5}{*}{ Sliding out the legs } \\
\hline 0.133062 & 0.361127 & 11 & \\
\hline 0.136019 & 0.362157 & 10 & \\
\hline 0.139087 & 0.355846 & 9 & \\
\hline 0.144151 & 0.350437 & 8 & \\
\hline 0.079837 & 0.363703 & 12 & \multirow{5}{*}{$\begin{array}{l}\text { Sliding down the canopy } \\
\text { support's actuator }\end{array}$} \\
\hline 0.152467 & 0.33515 & 11 & \\
\hline 0.146239 & 0.326003 & 10 & \\
\hline 0.146479 & 0.302624 & 9 & \\
\hline 0.16509 & 0.298607 & 8 & \\
\hline 0.101645 & 0.390316 & 12 & \multirow{5}{*}{$\begin{array}{l}\text { Sliding out the canopy } \\
\text { support's actuator, }\end{array}$} \\
\hline 0.116429 & 0.3382 & 11 & \\
\hline 0.120126 & 0.32752 & 10 & \\
\hline 0.157087 & 0.319867 & 9 & \\
\hline 0.166327 & 0.311976 & 8 & \\
\hline
\end{tabular}

\section{Conclusions}

The tests were carried out to determine the usable properties of an innovative electro hydraulic control system for the powered roof support. On the basis of the obtained results in the range of time charts for pressure coming from the valve piston from the space above the piston and under the piston, the voltage of the solenoid valve coils, time until the power supply is supplied to the solenoid valve until it opens, and delay, it is possible to conclude that the results obtained are very promising. The higher the value of the voltages taken for the desired function of the solenoid valve control, the better the parameter for the control function is obtained.

The tested innovative electro control system for powered roof supports is a more advantageous solution compared to the currently used control system. As a result, the next stage of development of innovative control systems should include carrying out operational tests in real conditions. The presented result indicate that such steps are necessary.

Applied methodology and the results obtained also make it possible to compare various power supply and control systems of the roof support's hydraulic system. This allows to determine the effectiveness and efficiency of these systems. It also allows capturing errors made in design assumptions, calculations and selection of control components. The proposed solution is one of the elements of currently built intelligent control systems for the powered roof support and fits the Przemysł 4.0 program which is intended to be based on advanced IT solutions. The development of intelligent control systems for powered roof 
support may in this case be a guarantee of the development of the industry and constitute a serious argument for its implementation.

\section{Acknowledgement}

The work was carried out within the project 'Innovative electro hydraulic control system for powered roof support'. POIR.01.01.01-00-1129/15. Intelligent Development Operational Programme 2014-2020 carried out by the National Centre for Research and Development.

\section{References}

1. J. Brodny, M. Tutak, SGEM Conference Proceedings, 2, 299 (2016)

2. J. Brodny, M. Tutak, SGEM Conference Proceedings, 1(2), 897 (2016)

3. J. Brodny, M. Tutak, E3S Web Conferences, 29, 2267 (2018)

4. J. Brodny, M. Tutak, IOP Conf. Series: Earth and Environmental Science, 95 (2017)

5. K. Stecuła, M. Tutak, J. Brodny, 17th International Multidisciplinary Scientific Geoconference SGEM 2017, 17(13), 93 (2017)

6. J. Brodny, S. Alszer, J. Krystek, M. Tutak, Archives of Control Sciences, 2, 197 (2017)

7. D. Szurgacz, J. Brodny. $17^{\text {th }}$ International multidisciplinary scientific geoconference SGEM 2017, 17, 47 (2017) 